\title{
Exploring integrative medicine for back and neck pain - a pragmatic randomised clinical pilot trial
}

\author{
Tobias Sundberg*1,6, Max Petzold², Per Wändell33, Anna Rydén ${ }^{4}$ and \\ Torkel Falkenberg1,5
}

\begin{abstract}
Address: ${ }^{1}$ Unit for Studies of Integrative Health Care - Karolinska Institutet, Department of Neurobiology, Care Sciences and Society, Division of Nursing, 14183 Huddinge, Sweden, ${ }^{2}$ Nordic School of Public Health, PO Box 12133, 40242 Göteborg, Sweden, ${ }^{3}$ Center for Family and Community Medicine - Karolinska Institutet, Department of Neurobiology, Care Sciences and Society, 14183 Huddinge, Sweden, ${ }^{4}$ Health Care Research Unit - Sahlgrenska University Hospital, Bruna Stråket 30, 41345 Göteborg, Sweden, ${ }^{5}$ Vidar Clinic Foundation, Research Unit, 15391 Järna, Sweden and 'Scandinavian College of Chiropractic, Research Unit, 16957 Solna, Sweden
\end{abstract}

Email: Tobias Sundberg* - tobias.sundberg@ki.se; Max Petzold - max.petzold@nhv.se; Per Wändell - per.wandell@ki.se; Anna Rydén - anna.ryden@medicine.gu.se; Torkel Falkenberg - torkel.falkenberg@ki.se

* Corresponding author

\section{Published: 7 September 2009}

BMC Complementary and Alternative Medicine 2009, 9:33 doi:10.1 186/1472-6882-9-33
Received: 16 February 2009

Accepted: 7 September 2009

This article is available from: http://www.biomedcentral.com/1472-6882/9/33

(C) 2009 Sundberg et al; licensee BioMed Central Ltd.

This is an Open Access article distributed under the terms of the Creative Commons Attribution License (http://creativecommons.org/licenses/by/2.0), which permits unrestricted use, distribution, and reproduction in any medium, provided the original work is properly cited.

\begin{abstract}
Background: A model for integrative medicine (IM) adapted to Swedish primary care was previously developed. The aim of this study was to explore the feasibility of a pragmatic randomised clinical trial to investigate the effectiveness of the IM model versus conventional primary care in the management of patients with non-specific back/neck pain. Specific objectives included the exploration of recruitment and retention rates, patient and care characteristics, clinical differences and effect sizes between groups, selected outcome measures and power calculations to inform the basis of a full-scale trial.
\end{abstract}

Methods: Eighty patients with back/neck pain of at least two weeks duration were randomised to the two types of care. Outcome measures were standardised health related quality of life (the eight domains of SF-36) complemented by a set of exploratory "IM tailored" outcomes targeting selfrated disability, stress and well-being (0-10 scales); days in pain (0-14); and the use of analgesics and health care over the last two weeks (yes/no). Data on clinical management were derived from medical records. Outcome changes from baseline to follow-up after 16 weeks were used to explore the differences between the groups.

Results: Seventy-five percent (80/107) of screened patients in general practice were eligible and feasible to enrol into the trial. Eighty-two percent (36/44) of the integrative and $75 \%(27 / 36)$ of the conventional care group completed follow-up after 16 weeks. Most patients had back/neck pain of at least three months duration. Conventional care typically comprised advice and prescription of analgesics, occasionally complemented with sick leave or a written referral to physiotherapy. IM care generally integrated seven treatment sessions from two different types of complementary therapies with conventional care over ten weeks. The study was underpowered to detect any statistically significant differences between the groups. One SF-36 domain showed a clinically relevant difference between groups that was also supported by a small distribution based effect size, i.e. vitality (-7.3 points, Cohen's $d-0.34)$ which was in favour of IM. There was a clinical trend between groups showing that IM contributed to less use of prescription and non-prescription 
analgesics (-II.7 and - 9.7 percent units respectively) compared to conventional care. Exploring clinically relevant differences and the SF-36 as the basis for a main outcome measure showed that the sample sizes needed per arm to adequately power a full-scale trial depended on the target domain, i.e. ranging from 60 (vitality) to 339 (role emotion).

Conclusion: This pilot study investigated the implementation of IM in the primary care management of non-specific back and neck pain. Recruiting patients and implementing IM in routine clinical practice was feasible. The results warrant further exploration into different perspectives and relevant combinations of outcome measures including the use of health resources, drugs and cost-effectiveness to help understand the relevance of IM in primary care. Future research should prioritise larger scale studies considering variability, pain duration and small to moderate treatment effects.

\section{Trial registration: Clinical trials NCT00565942}

\section{Background}

Research over the last few decades has reported an increased use of complementary therapies (CTs) [1-3] and an integration of CTs into mainstream medical settings, health care organisations and insurance plans [4-11]. These trends may present both new challenges and new opportunities for health care provision. In Sweden and elsewhere, major challenges include the great variety and quality of CT provision within health care and a lack of national and international recommendations of how integration of CTs with conventional care may be modelled [12]. This lack of conceptual models for delivering integrative medicine (IM) may partly be a result of a scarce evidence base in support of IM provision within public health care services. Most research studies have investigated different CTs in isolation, i.e. assessed specific efficacy of individual components in models of care. It remains largely unknown whether comprehensive IM models differ clinically or cost effectively from conventional care provision. Pragmatic trials investigating the comparative effectiveness of different models of care (each with several components) have been a reported priority to gain more understanding of IM in clinical practice $[13,14]$.

Back and neck pain are conventionally managed in primary care, impose high costs, disability and decreased quality of life, and are two of the most common conditions treated by CTs [15-18]. Previously it has been found that IM in acute low back pain management, where a choice of massage, chiropractic or acupuncture was added to usual care, was as effective as usual care alone [19]. It is currently unknown if sub-acute to chronic back pain, for which conventional medical care is often costly and of limited benefit, respond differently to IM.

The current study was part of a research project exploring IM vs. conventional primary care on a health systems level, i.e. targeting general model effectiveness in a clinical context [20].

We have previously reported the results from the development of a comprehensive IM model adapted to Swedish primary care [21]. Consequently, the next phase of this project, and the aim of this pilot study was to explore the feasibility of conducting a randomised clinical trial to compare the effectiveness of the developed IM model with conventional primary care management, i.e. treatment as usual, for patients with non-specific back/neck pain of subacute to chronic duration. The specific objectives included analytical exploration of recruitment and retention rates, patient and care characteristics, clinical differences and effect sizes between groups, selected outcome measures and power calculations supported by collected data to inform the basis of a full-scale trial. Additional objectives were to test the feasibility of assessment, consent and data collection procedures.

\section{Methods}

\section{Study design and setting}

This explorative pilot study was conducted as a pragmatic randomised clinical trial, purposely in the setting of four primary care units in south suburban Stockholm. The implementation area could to some extent be characterised by a socio-economic status of higher unemployment rates, lower incomes and more welfare support and sickness benefits compared to the average levels in Stockholm [22].

\section{Patients and randomisation}

Patients consulting general practitioners for back and/or neck pain were identified and screened for study inclusion by physicians in routine practice at participating primary care units from September 2004 to December 2005. Inclusion criteria were 18-65 years of age, low back and/or neck pain with or without headache of at least two weeks dura- 
tion, resident of Stockholm County, literate in Swedish, willing to be randomised, and if allocated to IM attend up to $10 \mathrm{CT}$ treatments during the study period and pay five Euros per treatment for the first six treatments after which no additional payment for CTs would be asked, i.e. a ceiling set at 30 Euros for patients to obtain all CT treatments in the study. Exclusion criteria included specific pathology and severe causes of back/neck pain such as malignant disease, vertebral fractures and severe or progressive neurological symptoms.

Potential participants were referred to the study's head general practitioner and telephoned by the research coordinator for a verification of eligibility, a study presentation and verbal informed consent of willingness to participate. Patients who fulfilled the inclusion criteria and had no exclusions were sent written study information, baseline questionnaires and an informed consent document. When the questionnaires and the written signed consent had been returned an assistant not involved in patient care randomly allocated the patient by a computer generated procedure with no blocking or stratification giving each participant equal probability to receive either continued usual care or the IM model of care. The research coordinator was informed about the allocation and then enrolled the patient.

\section{Interventions and providers}

Conventional management

All patients first met their general practitioners to receive conventional care treatment plans. The conventional care complied with the clinical practice routines of the participating primary care units and the Stockholm county council management guidelines [23]. The guidelines for non-specific spinal pain disorders typically recommended advice (stay active), drug prescription (analgesics), sick leave (limited) and physiotherapy (activity based) [23]. There was no explicit study constraint to the provided conventional care as the study aimed to pragmatically reflect the general practitioners' standard care and treatment as usual. The general practitioners (n 35) of four neighbouring primary care units were invited to the study based on their involvement in back and neck pain management and interest to participate.

\section{IM management}

The model for delivering IM has been extensively described elsewhere [21]. In short, after the conventional care treatment plans had been advised, the IM management included consensus based team conferences to select and integrate relevant CTs into the management over a period of up to 12 weeks. The IM care was provided by a multidisciplinary IM team coordinated by a gate keeping general practitioner with clinical knowledge and experience of CTs and eight senior licensed/certified CT provid- ers representing Swedish massage therapy, manipulative therapy*, shiatsu, acupuncture ${ }^{* *}$ and qigong, i.e. CTs with an emerging evidence base in general [24-33]. As treatments commenced, regular consensus case conferences followed, combining conventional and CT clinical reasoning in order to verify and improve the ongoing clinical management of the patient [21]. Patients did not participate during the consensus case conferences as it was considered more efficient for them to take part in the health care process by way of intermittent personal interaction with the IM provider team [21].

*Manipulative therapy was provided by a naprapath, one of several health care professions in Sweden utilising manipulation/mobilisation techniques to normalise joint and soft tissue dysfunction. Other common manipulative therapy providers in Sweden include osteopaths, chiropractors and orthopaedic manipulative physiotherapists. ${ }^{*}$ A practitioner of traditional Chinese medicine provided acupuncture.

\section{Outcome measures}

One of the research strategies prioritised by the IM team for this pilot study was to explore the feasibility of using an internationally standardised outcome measure in combination with a set of "IM tailored" outcomes in addition to qualitative exploration (data reported separately elsewhere) to adequately investigate the comprehensive IM intervention [21]. Here, the reliable and valid SF-36 questionnaire [34-36] was used to explore health-related quality of life domains (physical functioning, role physical, bodily pain, general health, vitality, social functioning, role emotional and mental health) where a score between 0 (worst) to 100 (best) was calculated for each dimension using standardised scoring systems. The IM tailored outcomes were eventually set to target self reported disability, stress, well-being, days in pain and the use of analgesics and health care. Numerical rating scales $(0-10)$, where 0 indicated no and 10 indicated maximum levels respectively, were used to assess current disability of activities in daily living due to back/neck pain, stress and well-being. The disability rating scale was slightly modified from the second dimension of the reliable, valid and responsive Bournemouth questionnaire for back/neck pain $[37,38]$. The main modifications were to not specify the exact daily activities and asking for current instead of average disability, i.e. "How much does your back/neck pain interfere with your daily activities?" The stress and well-being scales were considered face valid and chosen to reflect common question areas targeted by CT providers in clinical practice. The number of days in pain during a fixed period of time has been valued an important indicator of pain persistence [39]. Based on group consensus and pre-testing of the selected outcome measures we stipulated an appropriate recall period of two weeks. The same time frame was chosen for assessing the face valid outcomes of self 
reported use (yes/no) of analgesics and health care in terms of prescription and non-prescription analgesics, conventional care and complementary care (CTs out of study). The outcome changes between baseline and follow-up after 16 weeks were used to explore and compare the results between the IM and conventional care groups.

\section{Data collection}

Data were collected by postal questionnaires sent out two and six weeks post the intervention period, i.e. after 12 and 16 weeks respectively. The administration of questionnaires, including up to two reminders, were managed outside of the primary care units by research staff not involved in the clinical care of patients. Hence all providers of care were blinded to the patient questionnaires but not to treatment allocation. The patients' general practitioners documented the conventional care treatment plans whereas the IM team documented data on IM care in a separate medical record specifically developed for the study.

\section{Statistical procedures}

Quality of life data (SF-36 questionnaires) were digitally scanned by standardised procedures at Göteborgs Universitet (HRQL gruppen, Göteborg, Sweden). Other outcome data were double entered into EpiData 3.1 (EpiData Association, Odense, Denmark) by research assistants not involved in the clinical care of patients. After cleaning and validation the raw data was imported into Intercooled Stata $^{\mathrm{TM}}$ 9.2, (StataCorp, College Station, TX, USA) and SPSS $^{\text {тм }} 15.0$ (SPSS Inc, Chicago, IL, USA) for statistical analyses.

Numerical variables were summarised as means, standard deviations, mean differences and proportions of change between baseline and follow-up after 16 weeks. The Mann-Whitney test was used for statistical analyses of differences between the groups for ordinal data (numerical rating scales and quality of life) and the independent two sample t-test was used for analysing days in pain. Dichotomous variables were summarised as the proportions of patients using the different types of analgesics and health care at the different time points.

When testing cross-sectional group differences at baseline we used univariate analysis where the different outcome measurements were dependent variables and the group allocation independent. When assessing the differences in change over time between groups we used a multiple regression model with time point, group allocation and the interaction term (equal to 1 if the measurement was from the IM-group and taken at follow up, and equal to 0 otherwise). We chose to not adjust for other covariates in the analysis. For the analysis of difference in change over time between the groups a mixed model was applied to account for repeated values within patients. The difference was estimated as the interaction term being 1 if the measurement was from the IM-group and taken at follow-up, and 0 otherwise.

All patients were kept in their assigned groups. Patients lost to follow-up, i.e. observations with missing data, were excluded from the primary analyses. To comply with a more comprehensive intention-to-treat strategy we did a secondary analysis where the last observed measures were imputed for missing data. A significance level of 5\% was used and 95\% confidence intervals were reported. All pvalue calculations were two-tailed.

No previous data about our specific study population were available and the sample size for the pilot trial was based on a hypothesis of disability scores (exploratory outcome). The hypothesis included that 0-10 ratings of disability would be about equal in the two groups at baseline, around 5. It was decided to power the study to detect a mean improvement of at least 2 points in the integrative medicine group vs. 1 point in the conventional care group. This difference was hypothesised to be of clinical relevance in order for the IM model to be advisable at follow-up after 16 weeks. Applying 80\% power, significance level of $5 \%$ and assuming a standard deviation of 1.5 gave a sample size of 36 patients per treatment arm $(n=72)$ (STATA software). The sample size was increased to $\mathrm{n}=$ 80 , which was reasoned sufficient to give an initial estimate of proportion for this type of explorative study.

The research project was approved by the regional ethics committee at Karolinska Institutet (Dnr: 668-03, 650-04 and 121-32).

\section{Results \\ Recruitment and retention}

About $75 \%$ of patients seeking help for back/neck pain at the primary care units were eligible and feasible to include in the trial, i.e. in total 107 patients were assessed for eligibility to be able to include 80 patients in the study (Figure 1). Demographics and baseline characteristics were similar between the groups, most patients had back/neck pain of at least 3 months duration, and there were no statistically significant differences between the groups (Table $1)$. Of the recruited patients $82 \%(36 / 44)$ in the IM group and $75 \%(27 / 36)$ in the conventional care group completed follow-up after 16 weeks (Figure 1). There were nine or $25 \%(9 / 36)$ dropouts in the conventional care group and eight or $18 \%(8 / 44)$ dropouts in the IM group after 16 weeks (Figure 1). Age and gender characteristics of dropouts were similar between the groups, i.e. conventional care group (mean age $41 \pm 9.7$ years, seven women) and IM group (mean age $38 \pm 9.2$ years, five women) and there were no significant differences in outcome characteristics. 
Table I: Baseline characteristics of study participants by randomised groups

\begin{tabular}{|c|c|c|}
\hline & Conventional care $(n=36)$ & Integrative care $(n=44)$ \\
\hline Age, mean (SD) & $4 I . I(10.4)$ & $40.3(9.4)$ \\
\hline Female, \% & $72 \%$ & $73 \%$ \\
\hline EU nationality, \% & $89 \%$ & $81 \%$ \\
\hline \multicolumn{3}{|l|}{ Location of worst pain, $\%$} \\
\hline Low back & $53 \%$ & $52 \%$ \\
\hline Neck & $33 \%$ & $36 \%$ \\
\hline Low back and neck & $14 \%$ & $11 \%$ \\
\hline \multicolumn{3}{|l|}{ Duration of pain, \% } \\
\hline Two weeks to three months & $17 \%$ & $12 \%$ \\
\hline Three months or longer & $83 \%$ & $88 \%$ \\
\hline Days with pain over the last two weeks (0-I4), mean (SD) & I2.I (2.8) & $11.8(3.8)$ \\
\hline Disability due to back/neck pain $(0-10)^{a}$, mean (SD) & $5.4(2.6)$ & $5.4(3.0)$ \\
\hline Stress $(0-10)^{a}$, mean $(\mathrm{SD})$ & $5.2(2.7)$ & $5.6(2.7)$ \\
\hline Wellbeing $(0-10)^{a}$, mean (SD) & $4.8(1.9)$ & $5.1(2.3)$ \\
\hline Used prescription analgesics during the last two weeks, \% yes & $54 \%$ & $45 \%$ \\
\hline Used non-prescription analgesics during the last two weeks, \% yes & $57 \%$ & $63 \%$ \\
\hline Used conventional care during the last two weeks, $\%$ yes & $61 \%$ & $65 \%$ \\
\hline Used complementary care over the last two weeks, $\%$ yes & $26 \%$ & $20 \%$ \\
\hline \multicolumn{3}{|l|}{ SF-36 Health related quality of life ${ }^{b}$} \\
\hline Physical functioning, mean (SD) & $69.4(17.3)$ & $70.1(24.4)$ \\
\hline Role physical, mean (SD) & $21.5(33.4)$ & $29.0(35.3)$ \\
\hline Bodily pain, mean (SD) & $32.0(14.5)$ & $34.0(19.1)$ \\
\hline General health, mean (SD) & $55.1(18.6)$ & $56.4(24.0)$ \\
\hline Vitality, mean (SD) & $36.4(16.6)$ & $32.3(23.3)$ \\
\hline Social functioning, mean (SD) & $61.5(24.2)$ & $56.3(30.0)$ \\
\hline Role emotional, mean (SD) & $54.2(39.9)$ & $58.3(43.2)$ \\
\hline Mental health, mean (SD) & $63.1(19.3)$ & $61.1(21.2)$ \\
\hline
\end{tabular}

${ }^{a}$ The anchors for the numerical ratings scales were 0 (nothing) to 10 (maximum) levels of disability, stress and wellbeing respectively. ${ }^{b S F}-36$ quality of life domains, min-max score from 0 (worst) to 100 (best). SD, standard deviation. There were no statistically significant differences between the randomised groups.

About $80 \%$ of physicians from the same primary care unit as the head general practitioner referred patients to the trial compared to about $10 \%$ of general practitioners of the other primary care units.

\section{Outcome measures}

\section{Clinical differences and effect sizes between groups}

One SF-36 domain showed a clinically relevant difference between groups $[40,41]$ that was also supported by a small distribution based effect size [42], i.e. vitality (-7.3 points, Cohen's $d$-0.34) which was in favour of IM (Table $2)$. Self-rated disability and stress returned small clinical differences ( 0.7 and 1.2 points) and small effect sizes (Cohen's $d 0.23$ and 0.43 ) between groups supporting IM (Table 2). The clinical use of drugs and health resources showed a trend between groups that IM contributed to less use of prescription and non-prescription analgesics (11.7 and -9.7 percent units respectively) compared conventional care (Table 3 ).

Statistical differences, power analysis and sample size Both the IM and conventional primary care groups improved over time (Tables 2 and 3). The primary analysis showed that there was generally large response variability and that the study was underpowered to detect statistically significant differences between the groups for any of the selected outcome measures (Tables 2 and 3). The secondary analysis (intention-to-treat) where the last observed measures were imputed for missing data did not change the results with lack of statistically significant differences between the groups (data not shown).

Exploring clinically relevant differences and the use of SF36 as the basis for a main outcome measure in a full-scale trial, employing $80 \%$ power, a significance level of $5 \%$, a 10 points clinical difference in change over time between groups $[40,41]$ and the standard deviations derived from our pilot data, showed that the sample size needed per arm would range between 60 (vitality) to 339 (role emotional) for the trial to be adequately powered in relation to the main target domain.

\section{Characteristics of care}

The conventional care treatment plans were characterised by advice $(85 \%)$, prescription of analgesics $(50 \%)$, sometimes complemented with short-term sick leave (33\%) or a written referral to physiotherapy (26\%). The advice was given by the general practitioner and could be categorised into general, e.g. to stay active (33\%); the use of analgesics $(15 \%)$; or recommendations about physiotherapy (37\%). 


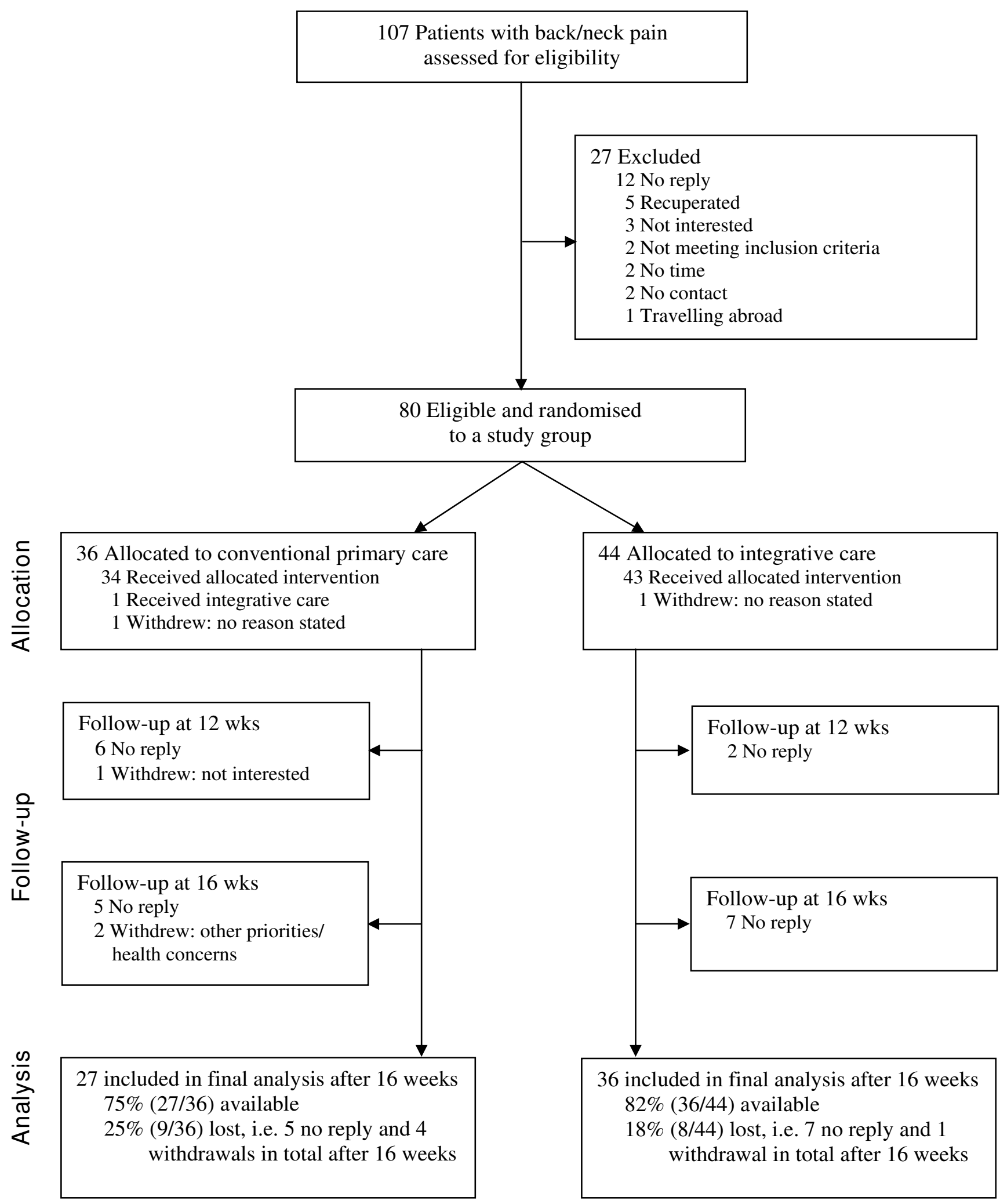

Figure I

CONSORT flow-chart. The flow of patients through the randomised clinical trial (CONSORT flow-chart). 
Table 2: Change in SF-36, numerical rating scales and days in pain from baseline to follow-up after 16 weeks

\begin{tabular}{|c|c|c|c|c|c|c|c|}
\hline \multirow[b]{2}{*}{ Outcome measure } & \multicolumn{2}{|c|}{ Conventional care } & \multicolumn{2}{|c|}{ Integrative care } & \multicolumn{3}{|c|}{ Conventional vs. integrative } \\
\hline & Mean (SD) & $\mathbf{N}$ & Mean (SD) & $\mathbf{N}$ & Diff. & d & $\mathbf{P}$ \\
\hline Physical functioning* & $11.0(16.8)$ & 27 & $9.1(13.2)$ & 35 & 1.9 & 0,09 & 0.920 \\
\hline Role physical* & $28.7(46.9)$ & 27 & $29.2(39.4)$ & 36 & -0.5 & $-0,01$ & 0.875 \\
\hline Bodily pain* & $19.1(22.5)$ & 27 & $21.2(23.4)$ & 36 & -2.1 & $-0,12$ & 0.813 \\
\hline General health* & $7.5(21.0)$ & 26 & $6.1(10.8)$ & 36 & 1.4 & 0,06 & 0.502 \\
\hline Vitality* & $12.1(16.6)$ & 27 & $19.4(21.8)$ & 35 & -7.3 & $-0,34$ & 0.237 \\
\hline Social functioning* & $13.4(21.9)$ & 27 & $14.6(2 \mid .0)$ & 36 & -1.2 & $-0,04$ & 0.703 \\
\hline Role emotional* & 16.I (44.7) & 27 & $8.3(48.1)$ & 36 & 7.7 & 0,18 & 0.872 \\
\hline Mental health* & $5.6(18.9)$ & 27 & $7.3(16.0)$ & 35 & -1.7 & $-0,09$ & 0.326 \\
\hline Disability (a) & $-1.2(3.5)$ & 26 & $-1.9(2.9)$ & 36 & 0.7 & 0,23 & 0.458 \\
\hline Stress (b) & $0.2(2.8)$ & 26 & $-0.9(2.2)$ & 36 & 1.2 & 0,43 & 0.090 \\
\hline Well-being (c) & $1.5(2.1)$ & 26 & $1.5(2.1)$ & 36 & -0.1 & $-0,03$ & 0.873 \\
\hline Days with pain (d) & $-3.1(4.7)$ & 26 & $-3.8(5.5)$ & 35 & 0.7 & 0,19 & 0.595 \\
\hline
\end{tabular}

*SF-36 health domains, min-max score from 0 (worst) to 100 (best). Numerical rating scales targeting; (a) disability in activities of daily living due to back/neck pain; (b) perceived stress; (c) well-being. The anchors for the numerical ratings scales were 0 (nothing) to 10 (maximum) levels of disability, stress and well-being respectively. (d) Days with pain over the last two weeks (0-14). SD, standard deviation. Diff, clinical difference between groups in outcome change over time (suggested magnitude for SF-36; 2 small, 5 clinically relevant, 10 moderate, 20 large [40,4I]). d, effect size by Cohen's d ( 0.20 small, 0.50 moderate and 0.80 large [42]). Statistical analyses by Mann-Whitney (numerical rating scales and SF-36) and independent two sample t-tests (days with pain).

Table 3: Change in self reported use of analgesics and health care from baseline to follow-up after 16 weeks

\begin{tabular}{|c|c|c|c|c|c|c|c|c|}
\hline \multirow[b]{2}{*}{$\begin{array}{r}\text { Type of health } \\
\text { resource }\end{array}$} & \multicolumn{3}{|c|}{ Conventional care } & \multicolumn{3}{|c|}{ Integrative care } & \multicolumn{2}{|c|}{$\begin{array}{l}\text { Conventional vs. } \\
\text { integrative care }\end{array}$} \\
\hline & From \% (n) & To \% (n) & Percent units & From \% (n) & To \% (n) & Percent units & Diff. & P OR $(95 \% \mathrm{Cl})$ \\
\hline $\begin{array}{r}\text { Prescription } \\
\text { analgesics }\end{array}$ & $\begin{array}{l}54.3 \% \\
(19 / 35)\end{array}$ & $\begin{array}{c}40.0 \% \\
(10 / 25)\end{array}$ & -14.3 & $\begin{array}{l}45.5 \% \\
(20 / 44)\end{array}$ & $\begin{array}{l}19.4 \% \\
(7 / 36)\end{array}$ & -26.0 & -11.7 & $\begin{array}{c}0.325 \\
0.34(0.0 \text { to } 3.0)\end{array}$ \\
\hline $\begin{array}{r}\text { Non-prescription } \\
\text { analgesics }\end{array}$ & $\begin{array}{l}57.1 \% \\
(20 / 35)\end{array}$ & $\begin{array}{c}42.3 \% \\
(11 / 26)\end{array}$ & -14.8 & $\begin{array}{l}63.4 \% \\
(26 / 41)\end{array}$ & $\begin{array}{c}38.9 \% \\
(14 / 36)\end{array}$ & -24.5 & -9.7 & $\begin{array}{c}0.703 \\
0.67(0.1 \text { to } 5.2)\end{array}$ \\
\hline $\begin{array}{r}\text { Conventional } \\
\text { care }\end{array}$ & $\begin{array}{l}61.1 \% \\
(22 / 36)\end{array}$ & $\begin{array}{l}15.4 \% \\
(4 / 26)\end{array}$ & -45.7 & $\begin{array}{l}65.1 \% \\
(28 / 43)\end{array}$ & $\begin{array}{l}22.2 \% \\
(8 / 36)\end{array}$ & -42.9 & 2.8 & $\begin{array}{c}0.720 \\
\text { I.38 (0.2 to 8.0) }\end{array}$ \\
\hline $\begin{array}{r}\text { Complementary } \\
\text { care }\end{array}$ & $\begin{array}{l}25.7 \% \\
(9 / 35)\end{array}$ & $\begin{array}{l}33.3 \% \\
(8 / 24)\end{array}$ & 7.6 & $\begin{array}{l}19.5 \% \\
(8 / 4 I)\end{array}$ & $\begin{array}{l}19.4 \% \\
(7 / 36)\end{array}$ & -0.1 & 7.5 & $\begin{array}{c}0.762 \\
0.75(0.1 \text { to } 4.8)\end{array}$ \\
\hline
\end{tabular}

All measures were for the self reported use over the last two weeks. Diff, difference in change over time between groups. OR, Odd's ratio. $\mathrm{Cl}$, confidence interval. 
The patients in the IM group additionally attended seven CT treatment sessions administered over a time period of ten weeks (Table 4). The division between western/body based CTs and eastern/energy based CTs were similar (Table 4). Among the energy based CTs acupuncture was less used than shiatsu (Table 4). On average the patients attended one session of individualised activity based selfhelp in the form of qigong (Table 4). Typically the patients received two different types of CTs (Table 5). Swedish massage was the most common therapy to be combined with several other types of CTs. Shiatsu and qigong were the two most common CTs to be combined together (Table 5). Manipulative therapy was the most common CT to be integrated as a single add-on treatment to conventional care (Table 5). There were no reports of crucial adverse events with either type of care.

The crude costs for the CT treatments in the IM model were approximated to $365 €$ (3320 SEK). These direct costs were calculated from estimates of non-reimbursed CT treatment costs in Sweden (figures derived from CT associations/representatives), i.e. Swedish massage $44 €$ (400 SEK), manipulative therapy $57 €(520$ SEK), shiatsu $53 €(480$ SEK), acupuncture $35 €(320$ SEK), and qigong $48 €(440$ SEK) in relation to the average number of CT treatments provided in the IM model (Table 4).

\section{Assessment, consent and data collection procedures}

Assessment and data collection procedures were feasible throughout the study. This included the physicians' screening of potential study participants during routine clinical practice, the referral to the head general practitioner and the verification of eligibility and obtaining oral and written informed consent. However, it was not possible to verify the total number of patients screened at the participating primary care units. Similarly, logistical barriers such as incompatibility between different providers' documentation and electronic patient record systems hindered mutual access to records of conventional or complementary care provided outside of the IM-team. Documentation of IM care was also challenging, e.g. in terms of standardisation of recording procedures, patient record contents and mutual terminology.

\section{Discussion}

\section{Recruitment and retention}

The patient recruitment process was feasible and resulted in a high success rate, i.e. $75 \%(80 / 107)$ of screened patients with back/neck pain were enrolled in the trial. Facilitators may have been general practitioner assurance, e.g. enforcing that they only had to screen regular patients and did not have to engage in the practicalities of enrolling the patients. The recruitment rate may however be an over estimation due to logistical barriers which prevented us from making direct comparison of the reported number of screened patients with the actual number of patients with back/neck pain having sought care at the participating primary care units. The head general practitioner's personal experience of professional CT provision, e.g. Swedish massage and acupuncture, may have been an additional recruitment facilitator. This was known to several of the collaborating physicians and may have increased their trust in the project and willingness to refer patients. Adding to this we found that physicians who worked at the same primary care unit as the head general practitioner referred the most patients to the trial. Perhaps regular informal contact among colleagues facilitated opportunities for queries and constructive dialogues in familiar biomedical terms about the rational for IM in primary care. Communicating in the same "language" in relation to biomedicine and CTs has indeed been suggested to increase understanding across different health care disciplines [43,44].

Patients lost to follow-up displayed similar characteristics between groups and were mostly due to no reply and attained 25\% (9/36) for conventional care and 18\% (8/ 44) for IM care after 16 weeks. One retention barrier may have been the use of postal questionnaires administered outside of the primary care units to collect data. Followup strategies "closer" to the patients, e.g. on-site questionnaires or interviews by dedicated staff members not involved in the clinical care of patients or follow-up pro-

Table 4: Categories, types and numbers of complementary treatments provided in the IM model during the treatment period

\begin{tabular}{ccccc}
\hline \multicolumn{2}{c}{ Western, body based } & \multicolumn{2}{c}{ Eastern, energy based } & Self help, activity based \\
\hline Swedish massage & Manipulative therapy* & Shiatsu & Acupuncture** & Qigong \\
\hline $1.5(2.7)$ & $1.8(2.6)$ & $2.8(3.4)$ & $0.3(1.6)$ & $1.0(1.8)$ \\
\hline & $1.6(2.6)$ & & $1.5(2.9)$ & \\
\hline
\end{tabular}

$7.3(3.2)$

Table figures refer to mean (standard deviation) estimates. The average length of the treatment period was I0.2 (I.4) weeks. *Manipulative therapy was provided by a naprapath. **A practitioner of traditional Chinese medicine provided acupuncture. 
Table 5: Combinations of complementary therapies provided in the IM model

\begin{tabular}{|c|c|c|c|}
\hline Categories & Types & Different CTs (n) & Patients \% (n) \\
\hline \multirow[t]{2}{*}{ Western } & Swedish massage & I & $6.8(3)$ \\
\hline & Manipulative therapy* & 1 & $22.7(10)$ \\
\hline \multirow[t]{2}{*}{ Eastern } & Shiatsu & 1 & $15.9(7)$ \\
\hline & Acupuncture ${ }^{* *}$ & 1 & $4.5(2)$ \\
\hline \multirow[t]{3}{*}{ Western + Eastern } & Manipulative therapy* + Shiatsu & 2 & II.4 (5) \\
\hline & Swedish massage + Shiatsu & 2 & $9.1(4)$ \\
\hline & Swedish massage + Acupuncture ${ }^{* *}$ & 2 & $2.3(1)$ \\
\hline Eastern + Self help & Shiatsu + Qigong & 2 & $13.6(6)$ \\
\hline \multirow[t]{2}{*}{ Western + Self help } & Swedish massage + Qigong & 2 & $6.8(3)$ \\
\hline & Manipulative therapy* + Qigong & 2 & $2.3(1)$ \\
\hline Western + Western & Swedish massage + Manipulative therapy* & 2 & $2.3(1)$ \\
\hline \multirow[t]{2}{*}{ Western + Eastern + Self help } & Manipulative therapy* + Shiatsu + Qigong & 3 & $2.3(1)$ \\
\hline & & Total & $100.0 \%(44)$ \\
\hline
\end{tabular}

Western, body based therapies: Swedish massage and manipulative therapy*. Eastern, energy based therapies: Shiatsu and acupuncture**. Self help, activity based therapy: Qigong. *Manipulative therapy was provided by a naprapath. ${ }^{* * A}$ practitioner of traditional Chinese medicine provided acupuncture.

cedures via telephone, might have been more feasible. However, a prerequisite for such strategies include the availability of resources and adequate funding which the current study did not have [21]. Additional facilitators for achieving high retention rates may include recruiting patients via media advertising or different health related registers, businesses or insurance companies. However, we decided against such external recruitment approaches reasoning that patients enrolled through active media advertising may behave differently (e.g. more motivated), have different socioeconomic characteristics and intentions for participating (e.g. more positive towards CTs) compared to the patients seeking regular care at their primary care units in a socioeconomically underpoverished suburban area. Hence the selected recruitment strategy may have increased the generalisability of findings in relation to the target population and clinical setting in the particular area, i.e. high external validity.

No patients dropped out due to crucial adverse effects with either type of care or due to the slight extra cost of receiving CTs in the IM model. This supports the IM and conventional care models as safe treatment options, as well as the feasibility of letting patients partly contribute to the costs for CT provision. This may have important clinical implications for implementation and sustainability of IM in public health care settings where CTs are not normally reimbursed. Future studies will have to investigate at what levels the economical thresholds lies and how much patients are willing to financially contribute for IM health services in different clinical settings.

\section{Characteristics and costs of care}

Conventional care provision complied with the recommended primary care guidelines [23]. To this the IM model integrated seven CT sessions over ten weeks, typically from two different CT types. The average number of CT treatments was about equally distributed between the western/body based and eastern/energy based CT categories. Acupuncture was the least provided CT, mainly due to difficulties recruiting an acupuncturist. The IM team compensated for this by providing shiatsu, a CT largely sharing the philosophy of acupuncture. The focus on selfhelp, activity based qigong therapy was an important component of the IM model that may have additional social/behavioural aspects worth exploring in future trials. 
Manipulative therapy was provided by a naprapath, a common provider of this type of care in Sweden. Future IM approaches may want to consider other recognised manipulative therapy professions including e.g. osteopaths, chiropractors and orthopaedic manipulative physiotherapists to facilitate the recruitment of manipulative therapy providers to IM teams.

The extra direct costs for CT treatments for achieving these clinical results was estimated to $365 €$ (3320 SEK) in total. However, this limited cost approximation did not include data on e.g. costs for conventional care, administration, case conferences, indirect costs or cost savings from patient, provider or organisational perspectives. Future studies are warranted and should consider collection of more detailed cost related data, e.g. by cost diaries and data base measures of health care visits and sick leave, to gain a thorough understanding about the costs and costeffectiveness of IM vs. conventional care. Such evidence has immediate implications for health policy and decision-making regarding the implementation of IM in conventional primary care.

\section{Outcomes}

The pilot trial analyses did not result in any statistically significant differences between the groups' outcome changes over time. Imputing missing data with the last observed measures (intention-to-treat) did not change the results, i.e. indicating that the chosen strategy was robust for excluding cases with missing data. Exploring outcome differences and effect sizes between the groups returned few clinically relevant differences. The outcome measures that displayed the largest clinical differences supporting IM, albeit within small ranges, were the SF-36 quality of life domain vitality and the decreased use of prescription and non-prescription analgesics. Clearly, less use of prescription analgesics if confirmed is an important clinical finding that may reduce reported negative side effects linked to prolonged use of such drugs [45,46]. Other small trends in favour of IM were seen in two of the exploratory IM tailored outcomes in terms of decreased disability and less stress. Perhaps the IM model due to the individualisation of back/neck pain management by integration of CTs facilitated additional and more personalized ways of supporting and empowering patients compared to possibilities within conventional care. However, the added CT treatments for the IM group might have exposed those patients to a more intensive management, which in turn may help to explain the trend towards more positive results for IM identified for some variables. This increased "attention" effect is purposively part of the IM model and allowed for in pragmatic and exploratory approaches towards investigating differences between models of care. The concurrent use of CTs out of the study allowed for in this pragmatic pilot study, although not actively recommended to patients (we sim- ply monitored their self-reported use), may have contaminated the trial and contributed to the lack of significant differences between groups. Nonetheless, to inflict or restrict self-initiated health care strategies or utilisation patterns, or to quantify and distinguish between placebo or non-specific effects of attention from more specific effects of e.g. isolated CT technologies or procedures, future studies would have to use more explanatory designs. Although such rather costly and complicated investigations would provide high internal validity, the generalisability of findings from such trials to regular primary health care provision can sometimes be questioned [20].

The current results with generally small clinical differences and effect sizes between groups may challenge a narrow use of outcomes measures in isolation to understand the relevance of IM in primary care. The findings may further attest to the need of identifying additional more relevant evaluation strategies, as suggested by recent outcomes research targeting IM and complex health interventions [47]. The trend of decreased use of prescription and non-prescription analgesics for IM in this pilot trial may support that the use of drugs and health care resources might indeed be one such important target area. Aspects of prevention, lifestyle changes and health promotion are other potentially important areas suggested, e.g. in recent research on shiatsu [48], incidentally one of the CTs in our IM model. Lastly, an iterative cycle integrating and triangulating complementing quantitative and qualitative investigative procedures might be one of the best approaches towards exploring complex interventions such as the implementation of IM in clinical care settings [49].

\section{Summary of strengths and limitations}

Strong points in this study were successful screening and recruitment procedures; feasible CT provision within conventional care; comprehensive results on the characteristics of IM care with expected high external validity; acquisition of data to explore statistical and clinical differences between groups and to adequately power a future large-scale trial. Limitations included a relatively high drop out rate after 16 weeks; underestimated variability and lack of power to detect statistically significant differences between the groups; no blocking in the randomisation procedure; several outcome measures of explorative nature lacking proper scientific validity; scarce results on the use of health care resources, costs and cost savings. We have discussed some implications of this for future research strategies including the need to continue investigations into relevant combinations of outcomes measures to adequately target and understand the relevance of IM for back and neck pain management in primary care settings. 


\section{Conclusion}

It has been proposed that for many patients the process of care may be as important as the outcomes of treatment [50] which may explain in part the relatively large utilisation of CTs among consumers and patients globally [51]. Indeed, care processes themselves may influence care outcomes, not merely in terms of satisfaction with care but also with respect to patients' state of health and treatment effectiveness [50]. Accordingly, the IM model emphasized care processes along with care outcomes, and considering some of the clinical trends reported here, aspects of IM care might be important to consider in primary health care reform. In conclusion this pilot study has demonstrated the feasibility of conducting a randomised clinical trial comparing a model for IM with conventional primary care management of patients with non-specific back/neck pain of mostly chronic duration. Recruiting regular primary care patients in routine clinical practice was feasible. Exploring clinically relevant differences and the use of SF-36 as the basis for a main outcome measure showed that the sample sizes needed per arm would range from 60 (vitality) to 339 (role emotion) to adequately power a full-scale trial. The findings attest to the need to further investigate IM as a complex health intervention and to continue to explore relevant combinations of outcomes to help understand the relevance of IM in primary care, e.g. by including patient and provider perspectives, detailed use of drugs and health care resources and health economic evaluations. Future research should prioritise larger scale studies considering variability, pain duration and small to moderate treatment effects.

\section{Competing interests}

Tobias Sundberg and Torkel Falkenberg are affiliated with the Unit for Studies of Integrative Health Care at Karolinska Institutet. Tobias Sundberg was financed by a grant from the Foundation for Manual Therapy Research (Insamlingsstiftelsen för forskning om manuella terapier) during the IM project. Per Wändell, Max Petzold and Anna Rydén declare no competing interests. The IM project was partly funded by the following Swedish organisations: Ekhagastiftelsen, Insamlingsstiftelsen för forskning om manuella terapier, and Svensk förening för vetenskaplig homeopati. The funding agencies did not have any influence on the design and conduct of the study; collection, management, analysis, and interpretation of the data; and preparation, review, or approval of the manuscript.

\section{Authors' contributions}

TS drafted the original manuscript and participated in redrafting and rewriting. TF conceived the general research design, critically read the manuscript and participated in redrafting and rewriting. MP outlined the statistical analyses, critically read the manuscript and participated in rewriting. PW provided primary care aspects, critically read the manuscript and participated in rewriting. AR helped with quality of life analyses, critically read the manuscript and participated in rewriting. All authors read and approved the final manuscript.

\section{Acknowledgements}

We would like to thank all patients and general practitioners at the primary care units of Bagarmossen, Skarpnäck, Björkhagen and Dalen that participated in the IM project. The following persons are gratefully acknowledged for their clinical commitment and participation in the IM project: Anders Warenmark, Jeremy Halpin, Jan Nevelius, Roger Jonsson, Mia Josjö, Cissi Douglas, Iris Lundby, Torun Tornesel and Susanne Andersson. Additionally, the following persons are appreciated for their valuable contribution during various phases: Renée Lidén, Lena Kahn, Stefan Göstasson, Vera Lind, AnnCathrine Carlander, Maria Warenmark, Eva Collin, Ulf Leander, Marie-Louise Munzing, Cecilia Norlin, Kjersti Knox, Peter Torssell, Jan Lindborg, Marian Papp, Eva Lundgren, Johanna Hök, Suzanne Schönström, David Finer, Maria Niemi, Riitta Hoffren-Larsson and Michaela Sobasjnikov.

\section{References}

I. Hanssen B, Grimsgaard S, Launso L, Fonnebo V, Falkenberg T, Rasmussen NK: Use of complementary and alternative medicine in the Scandinavian countries. Scand J Prim Health Care 2005, 23(I):57-62.

2. Eisenberg DM, Davis RB, Ettner SL, Appel S, Wilkey S, Van Rompay $M$, Kessler RC: Trends in alternative medicine use in the United States, I990-1997: results of a follow-up national survey. Jama 1998, 280( I 8): I 569-I575.

3. Tindle HA, Davis RB, Phillips RS, Eisenberg DM: Trends in use of complementary and alternative medicine by US adults: 1 997-2002. Altern Ther Health Med 2005, I I(I):42-49.

4. Barrett B, Marchand L, Scheder J, Plane MB, Maberry R, Appelbaum $D$, Rakel D, Rabago D: Themes of holism, empowerment, access, and legitimacy define complementary, alternative, and integrative medicine in relation to conventional biomedicine. Journal of alternative and complementary medicine (New York, NY) 2003, 9(6):937-947.

5. Cohen MM, Penman S, Pirotta M, Da Costa C: The integration of complementary therapies in Australian general practice: results of a national survey. Journal of alternative and complementary medicine (New York, NY) 2005, I I (6):995-1004.

6. Frenkel MA, Borkan JM: An approach for integrating complementary-alternative medicine into primary care. Fam Pract 2003, 20(3):324-332.

7. Landstingsförbundet: Den komplementära medicinens utbredning och tillämpning inom landets landsting. Örebro: Repro, Örebro Universitet; $200 \mathrm{I}$.

8. Paterson C, Peacock W: Complementary practitioners as part of the primary health care team: evaluation of one model. $\mathrm{Br}$ J Gen Pract 1995, 45(394):255-258.

9. Sipkoff M: Steadily, plans increase coverage of unorthodox medical therapies. Manag Care 2005, I4(8):59-60.

10. Sturm R, Unutzer J: State legislation and the use of complementary and alternative medicine. Inquiry 2000, 37(4):423-429.

II. Wolsko PM, Eisenberg DM, Davis RB, Ettner SL, Phillips RS: Insurance coverage, medical conditions, and visits to alternative medicine providers: results of a national survey. Arch Intern Med 2002, I 62(3):281-287.

12. Boon H, Verhoef M, O'Hara D, Findlay B: From parallel practice to integrative health care: a conceptual framework. $B M C$ Health Serv Res 2004, 4(I): I5.

13. Fonnebo V, Grimsgaard S, Walach H, Ritenbaugh C, Norheim AJ, MacPherson H, Lewith G, Launso L, Koithan M, Falkenberg T, et al.: Researching complementary and alternative treatments-the gatekeepers are not at home. BMC Med Res Methodol 2007, 7:7.

14. National Center for Complementary and Alternative Medicine (NCCAM): Expanding horizons of health care. Strategic Plan 
2005-2009. Bethesda, Maryland: NCCAM, National Institutes of Health; 2004.

15. Barnes PM, Bloom B, Nahin R: Complementary and Alternative Medicine Use Among Adults and Children: United States, 2007. In National Health Statistics Reports 12 Hyattsville. MD: National Center for Health Statistics; 2008.

16. Barnes PM, Powell-Griner E, McFann K, Nahin RL: Complementary and alternative medicine use among adults: United States, 2002. Adv Data 2004:1-19.

17. Ekman M, Johnell O, Lidgren L: The economic cost of low back pain in Sweden in $200 \mathrm{I}$. Acta Orthop 2005, 76(2):275-284.

18. Ekman $M$, Jonhagen $S$, Hunsche $E$, Jonsson $L$ : Burden of illness of chronic low back pain in Sweden: a cross-sectional, retrospective study in primary care setting. Spine 2005, 30(I5): I777-I785.

19. Eisenberg DM, Post DE, Davis RB, Connelly MT, Legedza AT, Hrbek AL, Prosser LA, Buring JE, Inui TS, Cherkin DC: Addition of choice of complementary therapies to usual care for acute low back pain: a randomized controlled trial. Spine 2007, 32(2): $|5|-\mid 58$.

20. Walach H, Falkenberg T, Fonnebo V, Lewith G, Jonas WB: Circular instead of hierarchical: methodological principles for the evaluation of complex interventions. BMC Med Res Methodol 2006, 6:29.

21. Sundberg T, Halpin J, Warenmark A, Falkenberg T: Towards a model for integrative medicine in Swedish primary care. BMC health services research 2007, 7:107.

22. Medborgarstatistik [http://www.stockholm.se/usk]

23. VISS - Vårdinformation StorStockholm, handläggning vid sjukdomar [http://www.viss.nu]

24. Field T, Hernandez-Reif M, Diego M, Schanberg S, Kuhn C: Cortisol decreases and serotonin and dopamine increase following massage therapy. Int J Neurosci 2005, I I 5(I 0):|397-|14|3.

25. Furlan AD, Imamura M, Dryden T, Irvin E: Massage for low-back pain. Cochrane Database Syst Rev 2008:CD001929.

26. Hsieh LL, Kuo CH, Lee LH, Yen AM, Chien KL, Chen TH: Treatment of low back pain by acupressure and physical therapy: randomised controlled trial. BMJ (Clinical research ed) 2006 332(7543):696-700.

27. Hurwitz EL, Carragee EJ, Velde G van der, Carroll LJ, Nordin M, Guzman J, Peloso PM, Holm LW, Cote P, Hogg-Johnson S, et al.: Treatment of neck pain: noninvasive interventions: results of the Bone and Joint Decade 2000-20 I 0 Task Force on Neck Pain and Its Associated Disorders. Spine 2008, 33(4 Suppl):SI23-152.

28. Kay TM, Gross A, Goldsmith C, Santaguida PL, Hoving J, Bronfort G: Exercises for mechanical neck disorders. Cochrane Database Syst Rev 2005:CD004250.

29. Skillgate $E$, Vingard E, Alfredsson L: Naprapathic manual therapy or evidence-based care for back and neck pain: a randomized, controlled trial. Clin J Pain 2007, 23(5):43I-439.

30. Furlan AD, van Tulder MW, Cherkin DC, Tsukayama $H$, Lao L, Koes BW, Berman BM: Acupuncture and dry-needling for low back pain. Cochrane Database Syst Rev 2005:CD00I35I.

31. Trinh KV, Graham N, Gross AR, Goldsmith CH, Wang E, Cameron ID, Kay T: Acupuncture for neck disorders. Cochrane Database Syst Rev 2006, 3:CD004870.

32. Yuan J, Purepong N, Kerr DP, Park J, Bradbury I, McDonough S: Effectiveness of acupuncture for low back pain: a systematic review. Spine 2008, 33(23): E887-900.

33. Lansinger B, Larsson E, Persson LC, Carlsson JY: Qigong and exercise therapy in patients with long-term neck pain: a prospective randomized trial. Spine 2007, 32(22):24I5-2422.

34. Persson LO, Karlsson J, Bengtsson C, Steen B, Sullivan M: The Swedish SF-36 Health Survey II. Evaluation of clinical validity: results from population studies of elderly and women in Gothenborg. J Clin Epidemiol I998, 5 I (I I): 1095-1 I03.

35. Sullivan M, Karlsson J: The Swedish SF-36 Health Survey III. Evaluation of criterion-based validity: results from normative population. J Clin Epidemiol 1998, 5 I ( I I): I 105-I I I3.

36. Sullivan M, Karlsson J, Ware JE Jr: The Swedish SF-36 Health Survey--I. Evaluation of data quality, scaling assumptions, reliability and construct validity across general populations in Sweden. Soc Sci Med 1995, 4 I ( I 0): I349-1358.

37. Bolton JE, Breen AC: The Bournemouth Questionnaire: a short-form comprehensive outcome measure. I. Psychomet- ric properties in back pain patients. J Manipulative Physiol Ther 1999, 22(8):503-510.

38. Bolton JE, Humphreys BK: The Bournemouth Questionnaire: a short-form comprehensive outcome measure. II. Psychometric properties in neck pain patients. J Manipulative Physiol Ther 2002, 25(3): $|4|-\mid 48$.

39. Von Korff M, Ormel J, Keefe FJ, Dworkin SF: Grading the severity of chronic pain. Pain 1992, 50(2): I33-149.

40. Sullivan M, Karlsson J, Taft C: Appendix F. In SF-36 Hälsoenkät: Svensk manual och tolkningsguide, 2:a upplagan Göteborg: Sahgrenska University Hospital; 2002.

4I. Ware J, Snow K, Kosinski M, Gandek B: SF-36 Health survey manual and interpretation guide. Volume 7:9-7. Boston, MA: New England Medical Center, The Health Institute; 1993:15.

42. Revicki DA, Cella D, Hays RD, Sloan JA, Lenderking WR, Aaronson NK: Responsiveness and minimal important differences for patient reported outcomes. Health Qual Life Outcomes 2006, 4:70.

43. Anderson R: A case study in integrative medicine: alternative theories and the language of biomedicine. J Altern Complement Med 1999, 5(2): 165-173. discussion 175-166

44. Caspi O, Bell IR, Rychener D, Gaudet TW, Weil AT: The Tower of Babel: communication and medicine: An essay on medical education and complementary-alternative medicine. Arch Intern Med 2000, 160(21):3193-3195.

45. Tramer MR, Moore RA, Reynolds DJ, McQuay HJ: Quantitative estimation of rare adverse events which follow a biological progression: a new model applied to chronic NSAID use. Pain 2000, 85(I-2): 169-| 82.

46. Hernandez-Diaz S, Garcia-Rodriguez LA: Epidemiologic assessment of the safety of conventional nonsteroidal anti-inflammatory drugs. Am J Med 200I, I I 0(SuppI 3A):20S-27S

47. Paterson C, Baarts C, Launso L, Verhoef M: Evaluating complex health interventions: a critical analysis of the 'outcomes' concept. BMC Complement Altern Med 2009, 9(I):18.

48. Long AF: The potential of complementary and alternative medicine in promoting well-being and critical health literacy: a prospective, observational study of shiatsu. BMC Complement Altern Med 2009, 9(I): 19

49. Campbell M, Fitzpatrick R, Haines A, Kinmonth AL, Sandercock $P$ Spiegelhalter D, Tyrer P: Framework for design and evaluation of complex interventions to improve health. Bmj 2000, 32 I(7262):694-696

50. Muir Gray JA: Evidence-Based Healthcare. How to Make Health Policy and Management Decisions. 2nd edition. London: Churchill Livingstone; 200 I.

51. World Health Organization: National policy on traditional medicine and regulation of herbal medicines. Report of a WHO global survey. Geneva: World Health Organization; 2005.

\section{Pre-publication history}

The pre-publication history for this paper can be accessed here:

\section{http://www.biomedcentral.com/1472-6882/9/33/prepub}

Publish with BioMed Central and every scientist can read your work free of charge

"BioMed Central will be the most significant development for disseminating the results of biomedical research in our lifetime. "

Sir Paul Nurse, Cancer Research UK

Your research papers will be:

- available free of charge to the entire biomedical community

- peer reviewed and published immediately upon acceptance

- cited in PubMed and archived on PubMed Central

- yours - you keep the copyright
BioMedcentral 